\title{
Incidence and Predictors of Neck and Widespread Pain after Motor Vehicle Collision among US Litigants and Non-Litigants
}

\author{
Samuel A. McLean, MD, MPH ${ }^{1,2,3}$, Jacob C. Ulirsch, BS ${ }^{1,2}$, Gary D. Slade, PhD $^{4}$, April C. \\ Soward, MPH ${ }^{1,2}$, Robert A. Swor, DO $^{5}$, David A. Peak, MD ${ }^{6}$, Jeffrey S. Jones, MD ${ }^{7}$, Niels K. \\ Rathlev, MD ${ }^{8}$, David C. Lee, MD ${ }^{9}$, Robert M. Domeier, MD ${ }^{10}$, Phyllis L. Hendry, MD ${ }^{11}$, \\ Andrey V. Bortsov, MD, $\mathrm{PhD}^{1,2}$, and Eric Bair, $\mathrm{PhD}^{4}$ \\ ${ }^{1}$ TRYUMPH Research Program, University of North Carolina, Chapel Hill, NC \\ ${ }^{2}$ Anesthesiology, University of North Carolina, Chapel Hill, NC \\ ${ }^{3}$ Emergency Medicine, University of North Carolina, Chapel Hill, NC \\ ${ }^{4}$ Dentistry, University of North Carolina, Chapel Hill, North Carolina \\ ${ }^{5}$ Emergency Medicine, William Beaumont Hospital, Royal Oak, Michigan \\ ${ }^{6}$ Emergency Medicine, Massachusetts General Hospital, Boston, Massachusetts \\ ${ }^{7}$ Emergency Medicine, Spectrum Health System, Grand Rapids, Michigan \\ ${ }^{8}$ Emergency Medicine, Baystate Medical Center, Springfield, Massachusetts \\ ${ }^{9}$ Emergency Medicine, North Shore University Hospital, Manhasset, New York \\ ${ }^{10}$ Emergency Medicine, Saint Joseph Mercy Health System, Ypsilanti, Michigan \\ ${ }^{11}$ Emergency Medicine, University of Florida, Jacksonville, Florida
}

\begin{abstract}
Debate continues regarding the influence of litigation on pain outcomes after motor vehicle collision (MVC). In this study we enrolled European Americans presenting to the emergency department (ED) in the hours after MVC ( $\mathrm{n}=948)$. Six weeks later, participants were interviewed regarding pain symptoms and asked about their participation in MVC-related litigation. The incidence and predictors of neck pain and widespread pain six weeks after MVC were compared among those engaged in litigation ("litigants") and those not engaged in litigation ("nonlitigants"). Among the 859/948 (91\%) participants completing six week follow-up, 711/849 (83\%) were non-litigants. Compared to non-litigants, litigants were less educated and had more severe neck pain, overall pain, and a greater extent of pain at the time of ED evaluation. Among individuals not engaged in litigation, persistent pain six weeks after MVC was common: 199/711
\end{abstract}

(C) 2013 International Association for the Study of Pain. Published by Elsevier B.V. All rights reserved. correspondence: Samuel McLean, MD, MPH, University of North Carolina, Medical School Wing C CB\#7010, Chapel Hill, NC 27599-7010.

Address for Reprints: Samuel McLean, MD, MPH, University of North Carolina, Medical School Wing C CB\#7010, Chapel Hill, NC 27599-7010, Phone: 919-843-5931, Fax: 919-966-7193, smclean@aims.unc.edu

Publisher's Disclaimer: This is a PDF file of an unedited manuscript that has been accepted for publication. As a service to our customers we are providing this early version of the manuscript. The manuscript will undergo copyediting, typesetting, and review of the resulting proof before it is published in its final citable form. Please note that during the production process errors may be discovered which could affect the content, and all legal disclaimers that apply to the journal pertain.

Scientific Meeting Presentation: None

Conflict of interest statement: Gary Slade, PhD, is a consultant at Algynomics, Inc. No other authors reported potential conflicts of interest. 
(28\%) had moderate or severe neck pain, 92/711 (13\%) had widespread pain, and 29/711 (4\%) had fibromyalgia-like symptoms. Incidence of all three outcomes was significantly higher among litigants. Initial pain severity in the ED predicted pain outcomes among both litigants and nonlitigants. Markers of socioeconomic disadvantage predicted worse pain outcomes in litigants but not non-litigants, and individual pain and psychological symptoms were less predictive of pain outcomes among those engaged in litigation. These data demonstrate that persistent pain after MVC is common among those not engaged in litigation, and provide evidence for bidirectional influences between pain outcomes and litigation after MVC.

\section{Introduction}

Motor vehicle collisions (MVCs) result in fifty million injuries worldwide and almost four million US emergency department (ED) visits each year [42; 62]. In the US, approximately $90 \%$ of individuals presenting to the ED after MVC are discharged to home after evaluation [46]. Persistent pain after MVC in this population is a common and costly public health problem [11].

Initial reports of persistent pain after MVC focused on neck pain, often termed "whiplash". This term was subsequently revised to Whiplash-Associated Disorders, due to evidence that symptoms after MVC include not only neck pain but also pain in adjacent body regions and other cognitive and somatic symptoms [57]. More recently, it has been demonstrated that pain after MVC may also be widespread [23; 26; 70; 71]. In addition, evidence suggests that fibromyalgia (FM) may also occur after MVC $[9 ; 35]$.

Compensation seeking has long been believed by some to be a dominant factor in complaints of persistent pain after MVC [18; 38; 52]. Others have pointed out that pain persistence after MVC may be associated with compensation seeking simply because those with worse health outcomes incur more costs from their condition and therefore are more likely to seek financial assistance [54;55]. The ongoing debate regarding the role of compensation has led to Whiplash-Associated Disorders being described as "one of the most controversial conditions in medicine" [10].

To help understand the influence of compensation seeking on pain after MVC, it would be useful to prospectively compare pain outcomes and predictors of persistent pain among individuals who are engaged vs. not engaged in compensation seeking. To date this has not been possible, because either the majority of study participants with persistent pain have been seeking compensation $[21 ; 28 ; 58]$ or because outcomes have evaluated time to insurance claim closure rather than pain symptoms directly [12; 14].

In this study we recruited individuals presenting to the ED in the hours after MVC in several "no fault" insurance states in the US, where litigation related to persistent post-MVC pain is more restricted [64], and prospectively compared the incidence and predictors of moderate or severe neck pain (MSNP) and widespread pain (WP) six weeks after the collision among individuals who are engaged vs. not engaged in compensation seeking. Six weeks after MVC is an important time point, because evidence suggests that individuals tend to establish a recovery set point four to ten weeks after MVC, which thereafter is more resistant to change $[5 ; 8 ; 27 ; 37 ; 59]$. We hypothesized that MSNP would be common after MVC among individuals not engaged in litigation, and that WP and FM-like symptoms would also occur among non-litigants. We also hypothesized that pain outcomes would be more common among those engaged in litigation. Consistent with the biopsychosocial model and with the potential contribution of stress systems modulated by supraspinal processes [34], we hypothesized that individual psychological, somatosensory, and cognitive characteristics, as well as sociodemographic and collision characteristics, would predict pain outcomes after 
MVC in both groups. Finally, we hypothesized that predictors of persistent pain among litigants and non-litigants would be similar.

\section{Methods}

\subsection{Design and setting}

This prospective longitudinal study enrolled patients presenting to the ED within 24 hours of MVC. Data were collected at eight EDs in four no-fault MVC litigation/insurance states (Michigan, Massachusetts, New York, and Florida) between February 2009 and October 2011. The study was approved by the institutional review boards of all participating hospitals, and each participant provided written informed consent. Complete information regarding study design, procedures, and methods has previously been described [45].

\subsection{Participant eligibility criteria and study sites}

Patients ages 18 to 65 who presented to the ED within 24 hours after a MVC and were unlikely to require hospitalization were screened for eligibility. Patients who were admitted to the hospital, had fractures other than phalangeal fractures, had more than 4 lacerations requiring sutures or a single laceration more than $20 \mathrm{~cm}$ in length, or had intracranial or spinal injuries were excluded. Spinal injury was defined by the presence of a fracture, dislocation, or new neurologic deficit. Enrollment was also limited to non-Hispanic whites (the most common ethnicity at study sites) because the study included the collection of genetic data and genetic analyses are potentially biased by population stratification [15]. Patients who were not alert and oriented were also excluded, as were pregnant patients, prisoners, patients unable to read and understand English, patients taking a $\beta$-adrenoreceptor antagonist, or patients taking opioids above a total daily dose of $20 \mathrm{mg}$ of oral morphine or equivalent.

\subsection{Study procedures}

Eligible and consenting participants completed ED interview evaluations regarding preMVC health status, the details of the MVC, and current symptoms. Interviews were conducted by research assistants at the time of the ED visit using a web-based survey with explicit definitions of variables. Before enrolling patients in the ED, each research assistant completed a study training module followed by an interview with a standardized mock ED patient. Comparison of mock ED patient data across research assistants demonstrated an error rate of $1.3 \%$. Injury characteristics and medications administered in the ED were obtained by data extraction from the ED medical record. Six weeks after the MVC, participants completed a follow up interview online, by telephone, or via mail. Regardless of follow up type, survey content was identical. Participants were compensated $\$ 50$ for completing the ED interview and $\$ 60$ for completing the 6 week interview.

\subsection{Measures}

A number of measures were used to assess health status prior to MVC and symptoms in the ED. Complete study measures are described in full elsewhere [45].

2.4.1 Participant demographics-Participant demographic characteristics (including age, gender, income, height, weight, and educational attainment) were obtained from the ED medical record and from participant self-report. Participant were also asked during the interview to report their current smoking status and if they had ever smoked tobacco. Health insurance coverage was obtained via self-report and classified as insured or not insured. 
2.4.2 Collision and injury characteristics—During the ED interview, participants completed a structured interview questionnaire evaluating collision characteristics; responses to this questionnaire have been shown to provide accurate collision information [32]. Collision characteristics assessed included seat belt use, air bag deployment, participant location in the vehicle, speed of the participant's vehicle, direction of vehicle impact, and extent of vehicle damage (rated by the participant as minor, moderate, or severe/ not drivable). Data regarding participant injury was abstracted from the ED medical record, including the presence and location of fractures of the phalanges (as described above, other fracture types resulted in participant exclusion), minor lacerations, contusions, avulsions, and abrasions. In addition, participants were also asked whether they believed the collision was their own fault, the fault of the other driver, or no one's fault.

2.4.3 Pain assessments and pain outcome definitions-Pain extent during the month prior to the MVC and in the ED were both assessed at the time of ED evaluation, pain extent six weeks after MVC was assessed at the six week timepoint. Pain extent was assessed in 19 discrete body regions evaluated in the regional pain scale [67] and in the head region. Individuals reporting $\geq 7$ bodily regions of pain were defined as having WP during that time period. This cut-off was selected to be consistent with 2010 American College of Rheumatology (ACR) criteria, which defines WP as 27 body regions of pain during the past week [68].

In each body region in which the participant reported pain, average pain severity was assessed using a verbal 0 to 10 numeric rating scale (NRS). Verbal scores have advantages in acute care settings, and verbally administered NRSs have been validated as highly correlated with visual analogue scale scores [39]. Regional pain was defined by the presence of one more body regions with a NRS score of $\geq 1$. MSNP six weeks after the initial ED visit was defined as MVC-related pain with a NRS score of $\geq 4[17 ; 31]$.

At the six week time point, average pain during the week prior to the interview was assessed. If a participant reported pain in a body region then they were also asked if the pain was due to the MVC. Only pain that was reported as present and subsequently reported as due to MVC was evaluated in analyses of six week pain outcomes. FM-like symptoms six weeks after MVC were defined by $\geq 8$ body regions of pain together with a fatigue severity score of $\geq 6(0-10$ NRS) in the past week [29;69]. This criteria has been shown to have $72.3 \%$ concordance with the 2006 ACR criteria for fibromyalgia [29].

2.4.4 Psychological symptoms-Pain catastrophizing was measured using the Pain Catastrophizing Scale [61]. This 13-item scale (combined score range 0 to 52) assesses an individual's tendency to experience fear, anxiety, and helplessness in response to pain [61]. Distress was assessed using the Peritraumatic Distress Inventory (PDI). This measure has high internal consistency $(0.75-0.76)$ and test-retest reliability (0.74) [7]. A PDI cut-off score of $\geq 23$ was used to define marked distress symptoms ("distress") [41]. Dissociation was defined by the Michigan Critical Events Perception Scale (MCEPS) [36]. This measure has high internal consistency (0.81) and strong correlation with the Peritraumatic Dissociative Experiences Questionnaire ( $\mathrm{r}=0.5$ ) [36], a validated measure of dissociation [33]. An MCEPS cut-off score of greater than 3.0 is indicative that the patient experienced dissociation [36]. Depressive symptoms during the week prior to the MVC were assessed using the Center for Epidemiologic Studies Depression Scale (CES-D) [47]. Based on previous evidence, CES-D scores between 16 and 25 were defined as mild depressive symptoms and scores greater than or equal to 26 were defined as severe depressive symptoms [65; 72]. Physical and mental health status during the 4 weeks prior to the MVC were assessed using the Mental Component Summary and Physical Component Summary scores of the Short-Form Health Survey version 2 (SF-12) [25]. Generalized optimism was 
assessed using the ten item Life Orientation Test - Revised (LOT-R) survey [51]. Only items $1,2,3,4,7,9$, and 10 are scored; the LOT-R has been shown to have good predictive and discriminant validity [51]. Trait anger and anxiety were assessed using the State-Trait Personality Inventory form Y (STPI-Y) anger and anxiety subscales [56]. To assess confidence in recovery, participants were asked "How certain, or sure, are you that you will fully recover from this accident" on a $0-10$ scale, where 0 denotes "certain you will not recover" and 10 denotes "certain you will recover fully". Participants were also asked to estimate how many days they expected it would take for them to recover physically and how many days they expected it would take for them to recover emotionally from the accident.

2.4.5 Somatic symptoms-ED somatic symptom burden was assessed by asking participants to rate the severity (0-10 NRS) of ten common post-traumatic symptoms [45]. Pre-MVC somatic symptom burden was also assessed in the ED by asking participants to rate the severity (0-10 NRS) of twenty one common somatic symptoms (e.g. nausea, dizziness, fatigue, ringing in ears, constipation or diarrhea) during the week prior to the MVC [45]. The total number of symptoms was calculated as the number of somatic symptoms with a response of $\geq 1$ (0-21 Pre-MVC, $0-10$ in the ED).

2.4.6 Litigation assessment-During the six-week follow-up assessment, participants were asked "Have you hired a lawyer, or are you working with a lawyer, because of injuries or other health problems that were related to your motor vehicle accident?" If participants answered yes, they were then asked if they were "suing for damages or workman's compensation?" Participants who answered yes to both questions were classified as "litigants" for the purpose of this analysis; others were classified as non-litigants.

\subsection{Statistical analyses}

Chi-square tests were performed in R [63] for contingency tables evaluating the null hypothesis that the percentage retained in the cohort at six weeks was equivalent for each group compared to baseline. Chi-square tests and Student's t-tests were used to assess differences in pain outcomes between litigants and non-litigants. Log-binomial regression with a robust estimation method was used to evaluate the association between each candidate predictor and primary outcome. Candidate predictor variable scores were categorized according to established cut-offs or (absent such cut-offs) divided into tertiles. Dummy variables for study site were included in each model. P-values in these bivariate analyses were reported from a likelihood ratio test for all levels of the putative risk factor. Estimates of the relative risk and associated 95\% confidence intervals (95\% CIs) were also calculated for each level of each putative risk factor. This analysis was performed separately for litigants and non-litigants. To test for differences in predictor strength by litigation status, bivariate log-binomial models were re-run for the combined cohort of litigants and non-litigants including a dummy variable for litigation status and an interaction term (litigation status * putative predictor) in $\mathrm{R}$ (significance level $\mathrm{p}<0.10$ ).

Predictors showing evidence of association with outcomes in bivariate analyses were used as candidate predictors in multivariate analyses. Evidence of association in bivariate analyses was identified using $\mathrm{p}<0.05$ for non-litigants and $\mathrm{p}<0.10$ for litigants $(\mathrm{p}<0.10$ was used for litigants, because the sample of litigants was substantially smaller). Multivariate analyses were performed using a Least Absolute Shrinkage and Selection Operator (LASSO). Lasso is a form of penalized regression that also performs variable selection and is useful for obtaining a set of predictors that are associated with an outcome while guarding against over-fitting. The tuning parameter for each model was chosen as one standard error (SE) below the model which maximizes the area under the receiver operating curve characteristic (AUROCC) curve without over fitting the model. All models were fit using the "glmnet" 
package in $\mathrm{R}$ [19]. As with most implementations of Lasso, in this package there is a lack of a consensus on how estimates should be interpreted. We chose to report the strongest sparse subset of predictors and derive risk ratios and 95\% CIs using log-binomial models that adjust for age, sex, and site, but not for other predictors in each given subset. For each Lasso model, the mean AUROCC curve from the cross-validation was also reported.

In secondary analyses that investigated the relationship between initial characteristics and the proportion of the study sample which pursued litigation, a generalized linear model was used to obtain least squares means (LS-means). Reported LS-means were controlled for age, sex, and state of participant residence (due to variation in no fault laws between states). Differences in one characteristics amongst a single category of another characteristic are known as simple effects [66] and were deemed significant if $\mathrm{p}<0.05$.

\section{Results}

\subsection{Baseline participant characteristics and characteristics of those completing six week follow-up evaluation}

A total of 10,629 patients were screened, 1,416 were eligible, 969 consented to study participation and 948 completed baseline evaluation (Figure 1). Slightly more than $60 \%$ of participants were female, more than three quarters had some education past high school, and more than half worked full time (Table 1). The median age of study participants was 36 (range 18-65). Fractures were present in $1 / 948(<1 \%$, phalanx fracture) participants, a small laceration was present in 53/948 (6\%) participants. The vast majority of study participants had musculoskeletal strain only. At the time of the ED visit, more than half of study participants had MSNP and nearly one in five had widespread pain (Table 1) [6].

Six week follow-up assessments were completed on 859/948 (91\%) of enrolled patients. There were small $(<2 \%)$ but statistically significant differences in the characteristics of participants who did and did not complete six week follow-up: study participants who did not complete six week follow-up evaluation were more likely to be younger, male, to smoke, and to have a lower socioeconomic status than patients completing 6 week follow-up evaluation (Table 1). In the overall cohort, $70 \%$ of participants reported pain in at least one body region six weeks after MVC and over one third reported pain in four or more body regions. The most common regions with moderate or severe pain were the neck, lower back, shoulder, and upper back (Figure 2).

\subsection{ED characteristics and six week pain outcomes among litigants and non-litigants}

Among the 859 participants who completed six week follow-up, 711/859 (83\%) had not hired a lawyer to sue for compensation. Compared to individuals who were not engaged in litigation, study participants who hired a lawyer had more severe neck pain in the ED (4.5 (3.2) vs $3.5(3.0), t=3.7(\mathrm{df}=855), \mathrm{p}=.0002)$, more severe overall pain in the ED (6.4 (2.2) vs $5.3(2.4), \mathrm{t}=4.7(\mathrm{df}=849), \mathrm{p}<.0001)$, had a greater extent of pain (mean (SD) body regions with pain $5.8(4.5)$ vs $5.0(3.6), \mathrm{t}=2.2(\mathrm{df}=858), \mathrm{p}=.0254)$, and were less educated (e.g. $31 \%$ of litigants vs. $21 \%$ of non-litigants had less than a high school education, $\mathrm{p}=.0039$ ). Persistent pain six weeks after MVC was common among individuals not engaged in litigation: 493/711 (69\%) reported pain related to the MVC in one or more body regions, 199/711 (28\%) had MSNP, 92/711 (13\%) had WP, and 29/711 (4\%) had FMlike symptoms. Among the 148/859 (17\%) study participants who had hired a lawyer to sue for compensation, rates of persistent pain six weeks after MVC were substantially higher: $141 / 148(95 \%)$ reported pain related to the MVC in one or more body region, 95/148 (64\%) had MSNP, in 61/148 (41\%) had WP, and 20/148 (14\%) had FM-like symptoms. (p < . 00001 for all incidence comparisons with non-litigants.) Of note, because the number of 
individuals with FM-like symptoms six weeks after MVC was relatively small ( $\mathrm{n}=29$ among non-litigants and $n=20$ among litigants), subsequent bivariate and multivariate analyses were limited to MSNP and WP only.

\subsection{Bivariate predictors of MSNP six weeks after MVC}

Initial bivariate analyses indicated that interactions were present between litigation status and the strength of association between some predictor variables and the development of MSNP six weeks after MVC. For this reason, predictors of six week pain outcomes between individuals litigating and not litigating were evaluated separately.

3.3.1 Demographic and collision characteristics-Associations between individual sociodemographic and crash characteristics and pain outcomes are shown in Figure 3A. Among individuals not engaged in litigation, female gender, older age, and extent of vehicle damage predicted the presence of MSNP six weeks after MVC. In addition, being in a car traveling 41-80mph was protective of MSNP vs. being in a stopped vehicle. Among individuals engaged in litigation, different factors predicted the presence or absence of MSNP. Full time employment, presence of health insurance, and being the vehicle driver all were protective against the development of MSNP in litigants.

3.3.2 Pain and somatic symptoms-Associations between pain and somatic symptoms reported prior to MVC and in the immediate aftermath of MVC and MSNP six weeks after MVC are shown in Figure 3B. Among individuals not engaged in litigation, pain and somatic symptoms in the ED were strong predictors of persistent MSNP. ED pain and somatic symptoms that predicted MSNP six weeks after MVC among non-litigants included the presence of moderate neck pain, severe neck pain, moderate overall pain, severe overall pain, any regional pain, any widespread pain, having post-MVC somatic symptoms in the middle vs. lowest tertile, and having post-MVC somatic symptoms in the highest vs. lowest tertile. In general, ED pain and somatic symptoms were less predictive of MSNP six weeks after MVC among individuals engaged in litigation. Being in the middle or highest tertile of somatic symptoms in the ED predicted MSNP in litigants, but overall pain severity and the presence of regional or WP in the ED did not. Neck pain severity in the ED predicted MSNP among litigants, but the strength of this association was weaker than among non-litigants. Being in the middle or highest tertile of past somatic symptom burden predicted MSNP in litigants, but not in non-litigants.

\subsubsection{Psychological and cognitive characteristics-Associations between} psychological and cognitive characteristics and MSNP six weeks after MVC are shown in Figure 3C. Among non-litigants, belief that the MVC was another person's fault (vs nobody's fault) increased risk of persistent pain. Among litigants, this association was not significant, likely because among litigants the belief that the MVC was nobody's fault was very uncommon (therefore confidence intervals were very wide). Among non-litigants, a number of psychological and cognitive characteristics predicted the presence of MSNP six weeks after MVC, including peritraumatic distress, peritraumatic dissociation, number of days that the individual estimated it would take to recover physically at the time of the ED visit, number of days that the individual estimated it would take to recover emotionally at the time of the ED visit, belief that the MVC was not the participant's fault, and high pain catastrophizing in the ED. Among individuals engaged in litigation, these factors were all less predictive of MSNP, with only increased catastrophizing score (highest vs. lowest quartile) significantly associated with persistent MSNP at the $p<0.05$ level. 


\subsection{Bivariate predictors of WP six weeks after MVC}

3.4.1 Demographic and collision characteristics-Individual predictors of WP six weeks after MVC, and differences in patterns of WP predictors between individuals engaged vs. not engaged in litigation were generally similar to those observed for MSNP. As with MSNP, older age and female sex increased risk of WP among non-litigants, but not among litigants (Figure 4A). As with MSNP, lack of health insurance predicted WP among litigants only.

3.4.2 Pain and somatic symptoms-Also as with MSNP, ED pain and somatic symptom characteristics were more predictive of WP among non-litigants than among litigants. Among non-litigants, history of neck pain during the month prior to MVC, moderate neck pain or severe neck pain in the ED in the hours after MVC, overall pain in the ED, WP in the ED, and number of somatic symptoms in the ED all predicted persistent WP six weeks after MVC (Figure 4B). Among litigants, only prior WP, WP in the ED, and number of somatic symptoms in the ED were predictive of WP six weeks after MVC. (A number of differences in the influence of pain and somatic symptoms on risk of WP after MVC according to litigation status reached statistical significance.)

3.4.3 Psychological and cognitive characteristics-Also consistent with findings regarding MSNP, among non-litigants peritraumatic dissociation, number of days estimated for emotional recovery, number of days estimated for physical recovery, number of days estimated for emotional recovery, and high pain catastrophizing predicted WP six weeks after MVC (Figure 4C). Point estimates indicated that these characteristics were less predictive of WP among litigants (e.g., high catastrophizing among litigants had a relative risk of 1.0, vs. 2.3 among non-litigants), and none of these factors significantly predicted WP six weeks after MVC among litigants (Figure 4C).

\subsection{Multivariate models}

From the bivariate predictors shown in Figure 3 and Figure 4, a parsimonious set of variables for predicting MSNP and WP were identified using Lasso regression. Among individuals not engaged in litigation, female sex, severe neck pain in the ED, and severe overall pain in the ED most efficiently predicted MSNP six weeks after MVC (Figure 5A, $\mathrm{CV}$ AUROCC $=0.73$ ). Among litigants, in addition to these variables, Lasso regression also selected lack of full time employment, lack of health insurance, rear end collision type, being a passenger vs driver, moderate neck pain in the ED, peritraumatic distress, a predisposition to anger (anger predisposition high vs. low tertile and middle vs. low tertile), and a higher participant age (42 to 65 years old vs. 18 to 27 years old) (Figure 5B, CV AUROCC $=0.73$ ). Of note, a number of individual predictors in the final multivariate model for litigants, including patient sex, age, moderate neck pain in the ED, peritraumatic distress, and both strata of anger predisposition were not significant in the log-binomial models controlling for site as well as age and sex (where appropriate). While not significant in these adjusted models, they are important as part of the sparse subset of factors determined by Lasso regression to maximize the AUROCC for MSNP amongst litigants.

Multivariate predictors of WP among non-litigants included neck pain and widespread pain in the ED, estimated time to recover physically in the $\mathrm{ED}$ (> 30 days vs. less than 7 days), and high vs. low pain catastrophizing (Figure 5C, mean CV AUROCC $=0.68$ ). Among individuals engaged in litigation, predictors of WP six weeks after MVC included a history of neck pain or WP during the month prior to MVC, presence of WP in the ED, and absence of health insurance (Figure 5D, CV AUROCC $=0.61$ ). 


\subsection{Secondary analyses in litigants}

Because the predictive influence of sociodemographic characteristics (e.g. income level, having health insurance) and initial pain characteristics (e.g. overall pain severity in the ED) seemed to vary by litigation status, we exploring these relationships in more detail. As shown in Figures 6A and 6B, as overall ED pain severity increased, the percentage of individuals litigating generally increased, regardless of health insurance status or income. However, individuals without any pain in the ED were more likely to litigate if they did not have health insurance (Figure 6A) or had an income of less than $\$ 40,000$ (Figure 6B).

\section{Discussion}

In this study we compared the incidence and predictors of MSNP and WP six weeks after MVC among litigants (148/859 (17\%)) and non-litigants (711/859 (83\%)). Compared to non-litigants, litigants were less educated and had more severe neck pain, overall pain, and a greater extent of pain at the time of ED evaluation. The incidence of pain outcomes was substantially higher among individuals engaged in litigation, however among individuals not engaged in litigation persistent pain six weeks after MVC was still common, and the majority of pain sequelae within the entire cohort occurred in non-litigants (68\% of MSNP, $60 \%$ of WP, and $59 \%$ of FM-like symptoms). Thus these data provide important evidence from a large patient cohort that post-MVC pain outcomes frequently occur among those who are not engaged in litigation.

Our study design does not provide us with a means to directly assess whether the increased incidence of MSNP and WP among litigants was due to (1) worse pain outcomes increasing likelihood of litigation, (2) litigation causing worse pain outcomes, or (3) bidirectional effects where (1) and (2) both occur. However, indirect evidence from this study suggests that bidirectional effects are most likely. Supporting hypothesis (1), initial pain symptom severity was greater among litigants, and initial pain symptom severity among litigants predicted pain outcomes among litigants as well as non-litigants. In addition, high pain catastrophizing in the ED, which may be considered a proxy of anticipated pain-related disability [53], predicted persistent MSNP in both groups. Supporting hypothesis (2), socioeconomic disadvantage was more predictive of adverse pain outcomes among litigants, suggesting that potential litigation-related monetary gain may (consciously or unconsciously) influence pain persistence or worsening pain. Also supporting hypothesis (2), individual pain and psychological characteristics were generally less predictive of pain outcome among those engaged in litigation, and individuals with no pain in the ED were more likely to litigate if they did not have health insurance or reported an annual household income of less than $\$ 40,000$. (Similar trends were observed for those with mild pain in the ED, but these differences did not reach statistical significance.) These results support a nuanced view of compensation system design, and suggest that systems at either extreme (systems which provide no opportunity for financial support for those with pain-related disability and systems which readily allow for any litigation) are unlikely to provide the most societal benefit.

Predictors of MSNP six weeks after MVC in this study, particularly among non-litigants, were consistent with risk factors identified in previous studies, including female sex [12; 20], pain and somatic symptom severity in the early aftermath of MVC [2; 12; 70], collision characteristics [3; 43], posttraumatic stress symptoms after MVC [2;30;60], and cognitive characteristics (estimated days to recover physically and emotionally, pain catastrophizing $[4 ; 24 ; 40])$. As with previous studies $[1 ; 60]$, pain severity in the immediate aftermath of MVC was a dominant predictor of subsequent pain outcomes. The fact that three bivariate predictors, which would be simple to assess clinically, provided good prediction of six week MSNP suggests that brief ED-based clinical instruments may be effective in identifying 
individuals at high risk of adverse pain outcomes at the time of the initial ED visit. If so, then this creates the opportunity to begin to test preventive interventions in high risk individuals identified at the time of their initial presentation for care. Such differential treatment based on risk profile has recently been shown to improve outcomes among individuals presenting to a primary care provider with low back pain [22].

Consistent with previous studies [23; 70], some patients in our cohort who experienced MVC developed WP. Among non-litigants, pain severity in the ED predicted WP, just as it predicted MSNP. However, unlike MSNP, WP among non-litigants was also predicted by extent of pain (WP) in the ED in the early aftermath of MVC. WP in the ED has been shown to be strongly associated with patient characteristics known to be modulated by supraspinal mechanisms [6], suggesting that individual neurobiologic factors which predispose an individual to stress-induced hyperalgesia in the hours after trauma also mark vulnerability to WP persistence. Further studies to identify biological factors associated with vulnerability to immediate and persistent WP after MVC are needed. Catastrophizing in the ED also predicted WP (but not MSNP) among non-litigants, suggesting that psychological or cognitive characteristics after the MVC, and/or other factors associated with catastrophizing, have a more important influence on WP than regional pain. To our surprise, assessment of bivariate and multivariate predictors among individuals engaged in litigation differed from individuals not engaged in litigation. Patterns of differences described above suggest that, compared to non-litigants, pain outcomes among litigants are more strongly influenced by socioeconomic factors and less influenced by initial pain and psychological symptom burden. For both MSNP and WP, optimal multivariate prediction models among litigants (but not non-litigants) included sociodemographic factors (for MSNP, employment and health insurance status, for WP, health insurance status). MSNP among litigants was also relatively more influenced by psychological factors and being a driver vs. passenger (the later potentially influenced by beliefs regarding fault). In general, multivariate prediction models for litigants included a greater number of predictors, but were less effective at predicting pain outcomes, suggesting that pain outcomes among litigants may be influenced by a more complex set of factors than pain outcomes among non-litigants.

A number of limitations should be considered when interpreting our results. First, differences in outcomes according to litigation status may vary depending on the permissiveness of the litigation environment. Therefore cohort studies conducted in other compensation and sociocultural environments are needed to better understand the generalizability of our results. A related limitation is that differences in the legal environment between states (e.g. interpretation of legal precedent, likelihood of attorney taking or keeping case), and/or potential geographic differences in clinical management, are unknown. In addition, the risk of false positive associations is increased by the fact that we did not adjust for multiple comparisons in our bivariate analyses. However, many of the candidate predictor variables assessed (e.g. psychological-related factors, pain-related factors) were correlated with one another, therefore adjusting for multiple tests would most likely result in a significant decrease in power with very little corresponding decrease in the risk of type I error [49]. In addition, the need for such adjustment is a matter of considerable debate $[16 ; 44 ; 48 ; 50]$, particularly in the setting of studies such as this one, in which candidate predictors were selected because substantial previous evidence suggests that they may be associated with study pain outcomes. Another limitation of this study is that selfreport information obtained from study participants might have been inaccurate or incomplete. However, baseline data were obtained at the time of initial evaluation, six weeks prior to the assessment of pain outcomes and litigation status, and sociodemographic variables and pain prior to MVC were more influential among individuals engaged in litigation, in whom reporting bias (conscious or unconscious) might be most incentivized. This suggests that reporting bias in providing information on candidate predictors was 
limited. Another limitation is potential bias in reporting six week pain outcomes. As noted in the introduction, the influence of litigation/active involvement in compensation on pain reporting is a contentious issue. Stratifying our analyses by litigation status at least allowed us to remove this potential concern from the majority of our (non-litigating) study participants. In addition, study participants were informed that our study data would remain confidential and were protected by a National Institute of Health Certificate of Confidentiality, and that our study data would not be accessible to them or other parties potentially involved in litigation. Another potential bias in our study is that is that, six weeks after MVC, individuals could falsely attribute musculoskeletal pain present prior to the collision as pain related to the MVC. However, evaluation of information obtained at the time of the initial ED visit indicates that only a small percentage of participants with adverse pain outcomes at six week reported such symptoms prior to MVC (15/294 (5\%) of those with MSNP, 9/153 (6\%) with WP, and 1/48 (2\%) of those developing FM-like symptoms). Finally, study outcomes were assessed six weeks after MVC, and the influence of litigation on pain outcomes at later time points is not known.

In conclusion, the results of this study indicate that adverse pain outcomes after MVC are common among individuals who are not engaged in litigation or compensation seeking, and that such adverse pain outcomes can be predicted by initial pain characteristics. In addition, our study results provide indirect evidence that post-MVC pain and litigation status have bidirectional influences on one another. Further research is needed to better understand the influence of litigation/compensation systems on pain outcomes after MVC. Such improved understanding is critical in order to design compensation systems around the world that most effectively promote pain recovery among the 50 million individuals [62] who are involved in a MVC annually.

\section{Acknowledgments}

We would like to thank the participants for taking part in this study. Research reported in this publication was supported by the National Institute of Arthritis and Musculoskeletal and Skin Diseases of the National Institutes of Health under Award Number R01AR056328. The content is solely the responsibility of the authors and does not necessarily represent the official views of the National Institutes of Health.

\section{References}

1. Atherton K, Wiles NJ, Lecky FE, Hawes SJ, Silman AJ, Macfarlane GJ, Jones GT. Predictors of persistent neck pain after whiplash injury. Emerg Med J. 2006; 23(3):195-201. [PubMed: 16498156]

2. Berglund A, Bodin L, Jensen I, Wiklund A, Alfredsson L. The influence of prognostic factors on neck pain intensity, disability, anxiety and depression over a 2-year period in subjects with acute whiplash injury. Pain. 2006; 125(3):244-256. [PubMed: 16806708]

3. Bjornstig U, Hildingsson C, Toolanen G. Soft-tissue injury of the neck in a hospital based material. Scand J Soc Med. 1990; 18(4):263-267. [PubMed: 2291100]

4. Bohman T, Cote P, Boyle E, Cassidy JD, Carroll LJ, Skillgate E. Prognosis of patients with whiplash-associated disorders consulting physiotherapy: development of a predictive model for recovery. BMC musculoskeletal disorders. 2012; 13:264. [PubMed: 23273330]

5. Borchgrevink GE, Lereim I, Royneland L, Bjorndal A, Haraldseth O. National health insurance consumption and chronic symptoms following mild neck sprain injuries in car collisions. Scandinavian Journal of Social Medicine. 1996; 24(4):264-271. [PubMed: 8983098]

6. Bortsov AV, Platts-Mills TF, Peak DA, Jones JS, Swor RA, Domeier RM, Lee DC, Rathlev NK, Hendry PL, Fillingim RB, McLean SA. Pain distribution and predictors of widespread pain in the immediate aftermath of motor vehicle collision. European journal of pain. 2013; 17(8):1243-1251. [PubMed: 23335385] 
7. Brunet A, Weiss DS, Metzler TJ, Best SR, Neylan TC, Rogers C, Fagan J, Marmar CR. The Peritraumatic Distress Inventory: a proposed measure of PTSD criterion A2. Am J Psychiatry. 2001; 158(9):1480-1485. [PubMed: 11532735]

8. Buitenhuis J, de Jong PJ, Jaspers JP, Groothoff JW. Relationship between posttraumatic stress disorder symptoms and the course of whiplash complaints. J Psychosom Res. 2006; 61(5):681-689. [PubMed: 17084147]

9. Buskila D, Neumann L, Vaisberg G, Alkalay D, Wolfe F. Increased rates of fibromyalgia following cervical spine injury. A controlled study of 161 cases of traumatic injury [see comments]. Arthritis \& Rheumatism. 1997; 40(3):446-452. [PubMed: 9082932]

10. Carette S. Whiplash injury and chronic neck pain. N Engl J Med. 1994; 330(15):1083-1084. [PubMed: 8127339]

11. Carroll LJ, Holm LW, Hogg-Johnson S, Cote P, Cassidy JD, Haldeman S, Nordin M, Hurwitz EL, Carragee EJ, van der Velde G, Peloso PM, Guzman J. Course and prognostic factors for neck pain in whiplash-associated disorders (WAD): results of the Bone and Joint Decade 2000-2010 Task Force on Neck Pain and Its Associated Disorders. Spine (Phila Pa 1976). 2008; 33(4 Suppl):S83S92. [PubMed: 18204405]

12. Cassidy JD, Carroll LJ, Cote P, Lemstra M, Berglund A, Nygren A. Effect of eliminating compensation for pain and suffering on the outcome of insurance claims for whiplash injury. New England Journal of Medicine. 2000; 342(16):1179-1186. [PubMed: 10770984]

13. Cherpitel CJ. Screening for alcohol problems in the emergency room: a rapid alcohol problems screen. Drug Alcohol Depend. 1995; 40(2):133-137. [PubMed: 8745135]

14. Cote P, Hogg-Johnson S, Cassidy JD, Carroll L, Frank JW. The association between neck pain intensity, physical functioning, depressive symptomatology and time-to-claim-closure after whiplash. Journal of Clinical Epidemiology. 2001; 54(3):275-286. [PubMed: 11223325]

15. Diatchenko L, Slade GD, Nackley AG, Maixner W. Responses to Drs. Kim and Dionne regarding comments on Diatchenko, et al. Catechol-O-methyltransferase gene polymorphisms are associated with multiple pain-evoking stimuli. Pain. 2006; 125:216-224. [PubMed: 16837133] Pain. 2007; 129(3):366-370. [PubMed: 17851590]

16. Feise RJ. Do multiple outcome measures require p-value adjustment? BMC Med Res Methodol. 2002; 2:8. [PubMed: 12069695]

17. Fejer R, Jordan A, Hartvigsen J. Categorising the severity of neck pain: establishment of cut-points for use in clinical and epidemiological research. Pain. 2005; 119(1-3):176-182. [PubMed: 16298059]

18. Ferrari R, Kwan O, Russell AS, Pearce JM, Schrader H. The best approach to the problem of whiplash? One ticket to Lithuania, please. Clinical \& Experimental Rheumatology. 1999; 17(3): 321-326. [PubMed: 10410265]

19. Friedman J, Hastie T, Tibshirani R. Regularization Paths for Generalized Linear Models via Coordinate Descent. J Stat Softw. 2010; 33(1):1-22. [PubMed: 20808728]

20. Harder S, Veilleux M, Suissa S. The effect of socio-demographic and crash-related factors on the prognosis of whiplash. Journal of Clinical Epidemiology. 1998; 51(5):377-384. [PubMed: 9619964]

21. Harris IA, Young JM, Jalaludin BB, Solomon MJ. Predictors of neck pain after motor vehicle collisions: a prospective survey. J Orthop Surg (Hong Kong). 2011; 19(3):317-321. [PubMed: 22184162]

22. Hill JC, Whitehurst DG, Lewis M, Bryan S, Dunn KM, Foster NE, Konstantinou K, Main CJ, Mason E, Somerville S, Sowden G, Vohora K, Hay EM. Comparison of stratified primary care management for low back pain with current best practice (STarT Back): a randomised controlled trial. Lancet. 2011; 378(9802):1560-1571. [PubMed: 21963002]

23. Holm LW, Carroll LJ, Cassidy JD, Skillgate E, Ahlbom A. Widespread pain following whiplashassociated disorders: incidence, course, and risk factors. The Journal of rheumatology. 2007; 34(1):193-200. [PubMed: 17143964]

24. Holm LW, Carroll LJ, Cassidy JD, Skillgate E, Ahlbom A. Expectations for recovery important in the prognosis of whiplash injuries. PLoS Med. 2008; 5(5):e105. [PubMed: 18479182] 
25. J Ware MK, Keller SD. SF-12: A 12-item Short-Form Health Survey: Construction of scales and preliminary tests of reliability and validity. Medical Care. 1996; 34:220-233. [PubMed: 8628042]

26. Jones GT, Nicholl BI, McBeth J, Davies KA, Morriss RK, Dickens C, Macfarlane GJ. Role of road traffic accidents and other traumatic events in the onset of chronic widespread pain: Results from a population-based prospective study. Arthritis Care Res (Hoboken). 2011; 63(5):696-701. [PubMed: 21425478]

27. Jonsson H Jr, Cesarini K, Sahlstedt B, Rauschning W. Findings and outcome in whiplash-type neck distortions. Spine. 1994; 19(24):2733-2743. [PubMed: 7899972]

28. Karnezis IA, Drosos GI, Kazakos KI. Factors affecting the timing of recovery from whiplash neck injuries: study of a cohort of 134 patients pursuing litigation. Archives of orthopaedic and trauma surgery. 2007; 127(8):633-636. [PubMed: 17487496]

29. Katz RS, Wolfe F, Michaud K. Fibromyalgia diagnosis: a comparison of clinical, survey, and American College of Rheumatology criteria. Arthritis and rheumatism. 2006; 54(1):169-176. [PubMed: 16385512]

30. Kongsted A, Bendix T, Qerama E, Kasch H, Bach FW, Korsholm L, Jensen TS. Acute stress response and recovery after whiplash injuries. A one-year prospective study. European journal of pain. 2008; 12(4):455-463. [PubMed: 17900949]

31. Krebs EE, Carey TS, Weinberger M. Accuracy of the pain numeric rating scale as a screening test in primary care. J Gen Intern Med. 2007; 22(10):1453-1458. [PubMed: 17668269]

32. Lee YM, Platts-Mills TF, Macwilliams JB, Sochor MR, Jones JS, Domeier RM, Schneider LW, McLean SA. Descriptions of motor vehicle collisions by participants in emergency departmentbased studies: are they accurate? West J Emerg Med. 2012; 13(4):329-334. [PubMed: 22942933]

33. Marmar CR, Weiss DS, Schlenger WE, Fairbank JA, Jordan BK, Kulka RA, Hough RL. Peritraumatic dissociation and posttraumatic stress in male Vietnam theater veterans. The American journal of psychiatry. 1994; 151(6):902-907. [PubMed: 8185001]

34. McLean SA, Clauw DJ, Abelson JL, Liberzon I. The development of persistent pain and psychological morbidity after motor vehicle collision: integrating the potential role of stress response systems into a biopsychosocial model. Psychosomatic Medicine. 2005; 67(5):783-790. [PubMed: 16204439]

35. McLean SA, Williams DA, Clauw DJ. Fibromyalgia after motor vehicle collision: evidence and implications. Traffic Inj Prev. 2005; 6(2):97-104. [PubMed: 16019393]

36. Michaels AJ, Michaels CE, Moon CH, Smith JS, Zimmerman MA, Taheri PA, Peterson C. Posttraumatic stress disorder after injury: impact on general health outcome and early risk assessment. J Trauma. 1999; 47(3):460-466. discussion 466-467. [PubMed: 10498298]

37. Miettinen T, Airaksinen O, Lindgren KA, Leino E. Whiplash injuries in Finland--the possibility of some sociodemographic and psychosocial factors to predict the outcome after one year. Disabil Rehabil. 2004; 26(23):1367-1372. [PubMed: 15742982]

38. Miller H. Accident neurosis. BMJ (Clinical research ed). 1961; i:919-925. 992-998.

39. Mohan H, Ryan J, Whelan B, Wakai A. The end of the line? The Visual Analogue Scale and Verbal Numerical Rating Scale as pain assessment tools in the emergency department. Emergency Medicine Journal. 2010; 27(5):372-375. [PubMed: 20442167]

40. Nederhand MJ, Ijzerman MJ, Hermens HJ, Turk DC, Zilvold G. Predictive value of fear avoidance in developing chronic neck pain disability: consequences for clinical decision making. Arch Phys Med Rehabil. 2004; 85(3):496-501. [PubMed: 15031840]

41. Nishi D, Matsuoka Y, Yonemoto N, Noguchi H, Kim Y, Kanba S. Peritraumatic Distress Inventory as a predictor of post-traumatic stress disorder after a severe motor vehicle accident. Psychiatry Clin Neurosci. 2010; 64(2):149-156. [PubMed: 20447011]

42. Niska R, Bhuiya F, Xu J. National Hospital Ambulatory Medical Care Survey: 2007 emergency department summary. Natl Health Stat Report. 2010; (26):1-31. [PubMed: 20726217]

43. Otremski I, Marsh JL, Wilde BR, McLardy Smith PD, Newman RJ. Soft tissue cervical spinal injuries in motor vehicle accidents. Injury. 1989; 20(6):349-351. [PubMed: 2628332]

44. Perneger TV. What's wrong with Bonferroni adjustments. BMJ. 1998; 316(7139):1236-1238. [PubMed: 9553006] 
45. Platts-Mills TF, Ballina L, Bortsov AV, Soward A, Swor RA, Jones JS, Lee DC, Peak DA, Domeier RM, Rathlev NK, Hendry PL, McLean SA. Using emergency department-based inception cohorts to determine genetic characteristics associated with long term patient outcomes after motor vehicle collision: methodology of the CRASH study. BMC Emerg Med. 2011; 11:14. [PubMed: 21943293]

46. Platts-Mills TF, Hunold KM, Esserman DA, Sloane PD, McLean SA. Motor vehicle collisionrelated emergency department visits by older adults in the United States. Academic emergency medicine : official journal of the Society for Academic Emergency Medicine. 2012; 19(7):821827. [PubMed: 22724382]

47. Radloff L. The CES-D Scale. A self-report depression scale for research in the general population. Applied Psychological Measurement. 1977; 1:385-401.

48. Rothman KJ. No adjustments are needed for multiple comparisons. Epidemiology. 1990; 1(1):4346. [PubMed: 2081237]

49. Sainani K. The importance of accounting for correlated observations. Pm R. 2010; 2(9):858-861. [PubMed: 20869686]

50. Savitz DA, Olshan AF. Describing data requires no adjustment for multiple comparisons: a reply from Savitz and Olshan. Am J Epidemiol. 1998; 147(9):813-814. discussion 815. [PubMed: 9583710]

51. Scheier MF, Carver CS, Bridges MW. Distinguishing optimism from neuroticism (and trait anxiety, self-mastery, and self-esteem): a reevaluation of the Life Orientation Test. J Pers Soc Psychol. 1994; 67(6):1063-1078. [PubMed: 7815302]

52. Schrader H, Obelieniene D, Bovim G, Surkiene D, Mickeviciene D, Miseviciene I, Sand T. Natural evolution of late whiplash syndrome outside the medicolegal context. Lancet. 1996; 347(9010): 1207-1211. [PubMed: 8622449]

53. Severeijns R, Vlaeyen JW, van den Hout MA, Weber WE. Pain catastrophizing predicts pain intensity, disability, and psychological distress independent of the level of physical impairment. The Clinical journal of pain. 2001; 17(2):165-172. [PubMed: 11444718]

54. Spearing NM, Connelly LB, Gargett S, Sterling M. Does injury compensation lead to worse health after whiplash? A systematic review. Pain. 2012; 153(6):1274-1282. [PubMed: 22521227]

55. Spearing NM, Connelly LB, Nghiem HS, Pobereskin L. Research on injury compensation and health outcomes: ignoring the problem of reverse causality led to a biased conclusion. Journal of clinical epidemiology. 2012; 65(11):1219-1226. [PubMed: 23017639]

56. Spielberger C. Preliminary manual for the State - Trait Personality Inventory (STPI). 2000

57. Spitzer WO, Skovron ML, Salmi LR, Cassidy JD, Duranceau J, Suissa S, Zeiss E. Scientific monograph of the Quebec Task Force on Whiplash-Associated Disorders: redefining "whiplash" and its management. Spine. 1995; 20(8 Suppl):1S-73S. [PubMed: 7604354]

58. Sterling M. Differential development of sensory hypersensitivity and a measure of spinal cord hyperexcitability following whiplash injury. Pain. 2010; 150(3):501-506. [PubMed: 20594646]

59. Sterling M, Hendrikz J, Kenardy J. Similar factors predict disability and posttraumatic stress disorder trajectories after whiplash injury. Pain.

60. Sterling M, Jull G, Vicenzino B, Kenardy J, Darnell R. Physical and psychological factors predict outcome following whiplash injury. Pain. 2005; 114(1-2):141-148. [PubMed: 15733639]

61. Sullivan MJL, Bishop SR, Pivik J. The Pain Catastrophizing Scale: Development and validation. Psychol Assessment. 1995; 7(4):524-532.

62. Tanskanen A, Hintikka J, Honkalampi K, Haatainen K, Koivumaa-Honkanen H, Viinamaki H. Impact of multiple traumatic experiences on the persistence of depressive symptoms - a population-based study. Nord J Psychiat. 2004; 58(6):459-464.

63. Team RDC. R: A language and environment for statistical computing. Vienna, Austria: R Foundation for Statistical Computing; 2011.

64. United States. Office of the Secretary of Transportation. Compensating auto accident victims : a follow-up report on no-fault auto insurance experiences. Washington, D.C.: Dept. of Transportation, Office of the Secretary of Transportation; 1985.

65. Weissman MMSD, Pottenger M, et al. Assessing depressive symptoms in five psychiatric populations: a validation study. Am J Epidemiol. 1977; 106:203-214. [PubMed: 900119] 
66. Winer, BJ. Statistical principles in experimental design. New York: McGraw-Hill; 1971.

67. Wolfe F. Pain extent and diagnosis: development and validation of the regional pain scale in 12,799 patients with rheumatic disease. The Journal of rheumatology. 2003; 30(2):369-378. [PubMed: 12563698]

68. Wolfe F, Clauw DJ, Fitzcharles MA, Goldenberg DL, Katz RS, Mease P, Russell AS, Russell IJ, Winfield JB, Yunus MB. The American College of Rheumatology preliminary diagnostic criteria for fibromyalgia and measurement of symptom severity. Arthritis Care Res (Hoboken). 2010; 62(5):600-610. [PubMed: 20461783]

69. Wolfe F, Rasker JJ. The Symptom Intensity Scale, fibromyalgia, and the meaning of fibromyalgialike symptoms. The Journal of rheumatology. 2006; 33(11):2291-2299. [PubMed: 16960921]

70. Wynne-Jones G, Jones GT, Wiles NJ, Silman AJ, Macfarlane GJ. Predicting new onset of widespread pain following a motor vehicle collision. The Journal of rheumatology. 2006; 33(5): 968-974. [PubMed: 16541476]

71. Wynne-Jones G, Macfarlane GJ, Silman AJ, Jones GT. Does physical trauma lead to an increase in the risk of new onset widespread pain? Annals of the Rheumatic Diseases. 2006; 65(3):391-393. [PubMed: 16014672]

72. Zich JM, Attkisson CC, et al. Screening for depression in primary care clinics: the CES-D and the BDI. Int J Psychiatry Med. 1990; 20(3):259-277. [PubMed: 2265888] 


\section{Summary}

Most individuals with pain sequelae six weeks after MVC are not engaged in litigation. Evidence supports bidirectional effects between litigation and post-MVC musculoskeletal pain outcomes. 


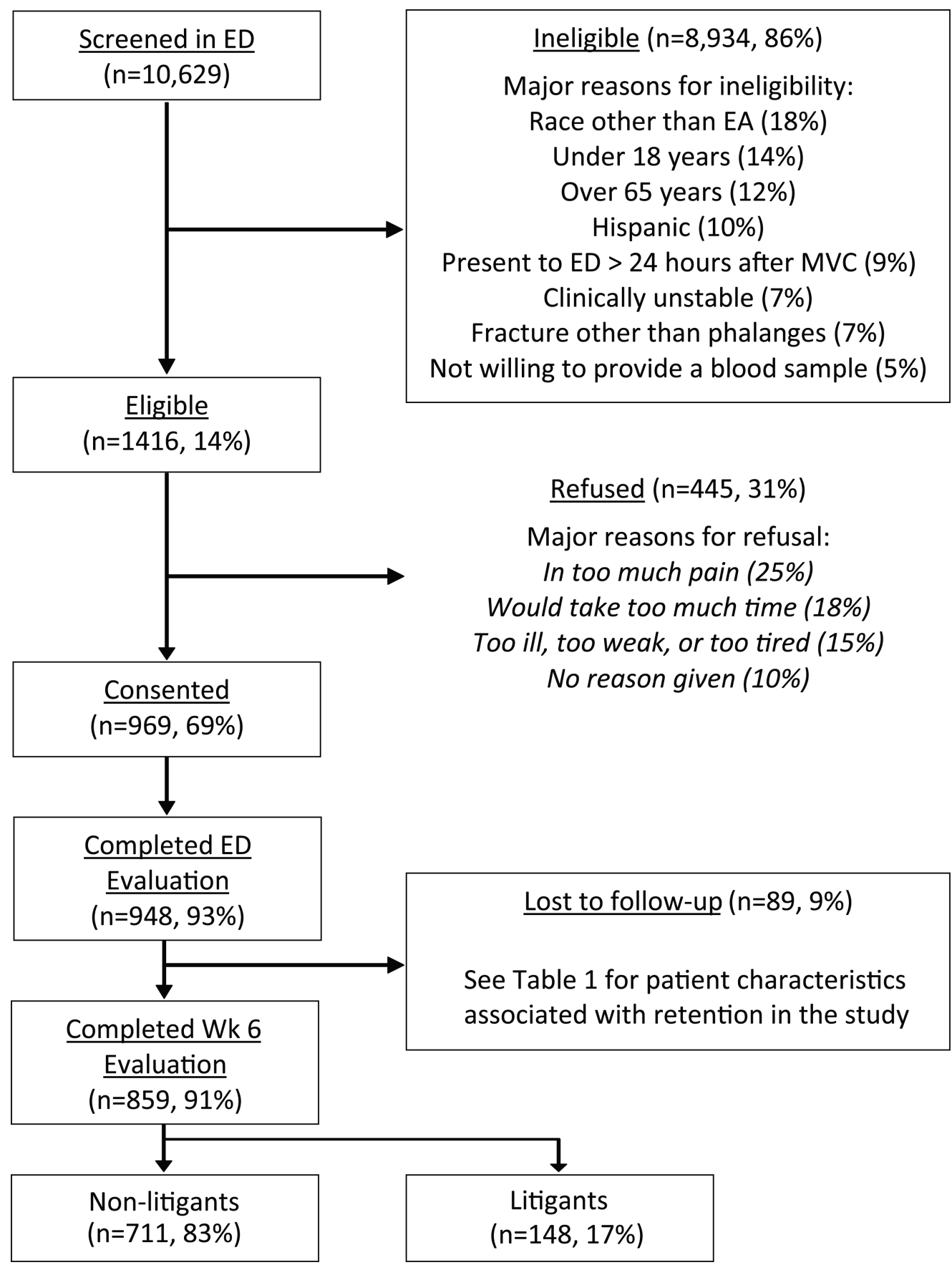

Figure 1.

A flow chart of the cohort reported on in this study. At the top, potential participants screened at participing EDs and the reasons for exclusions. The number eligible is reported next, and reasons for refusal to participate in the study are listed. Enrolled participants, participants retained at six weeks, and participants involved in litigation are shown at the bottom. 


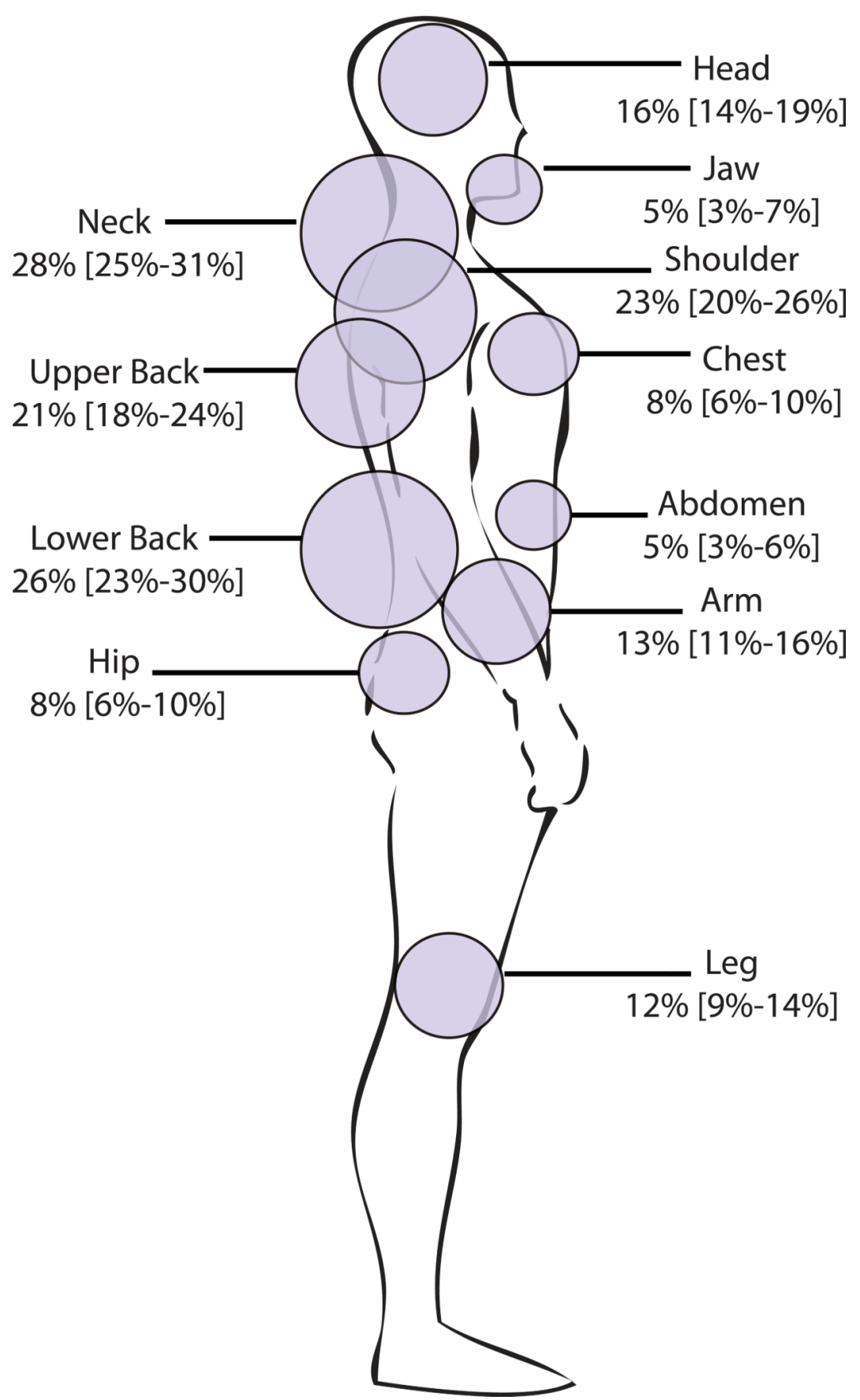

Figure 2.

Percentage of study participants with moderate or severe musculoskeletal pain (NRS $\geq 4)$ according to body region six weeks after motor vehicle collision (study participants not engaged in litigation only). 
A sociodemographic and CRASH characteristics

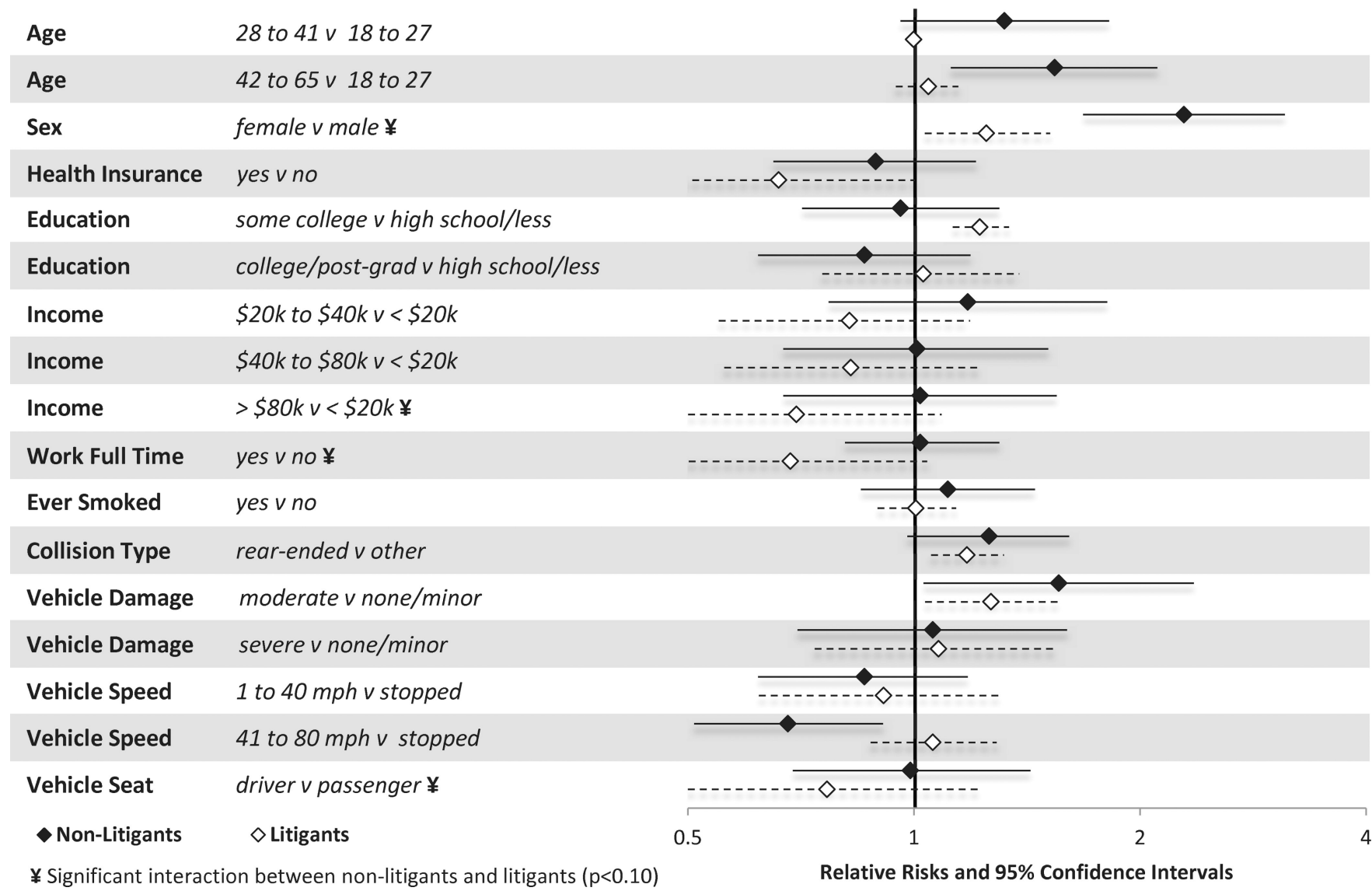

B Pain and Somatic Symptoms Reported Prior to MVC and immediately after MVC

Prior Neck Pain

Any Prior Regional Pain

Prior Widespread Pain

Prior Somatic Symptoms

Prior Somatic Symptoms

Overall Pain in the ED

Overall Pain in the ED

Widespread Pain in the ED

Any Regional Pain in the ED

Neck Pain in the ED

Neck Pain in the ED

Somatic Symptoms in the ED

Somatic Symptoms in the ED present $v$ absent

present $v$ absent

present $v$ absent

middle $v$ low

high v low

moderate $v$ none/mild

severe $v$ none/mild

present $v$ absent $¥$

present $v$ absent

moderate $v$ none/mild $¥$

severe $v$ none/mild $¥$

middle $v$ low

high $v$ low

$¥$ Significant interaction between non-litigants and litigants $(p<0.10)$

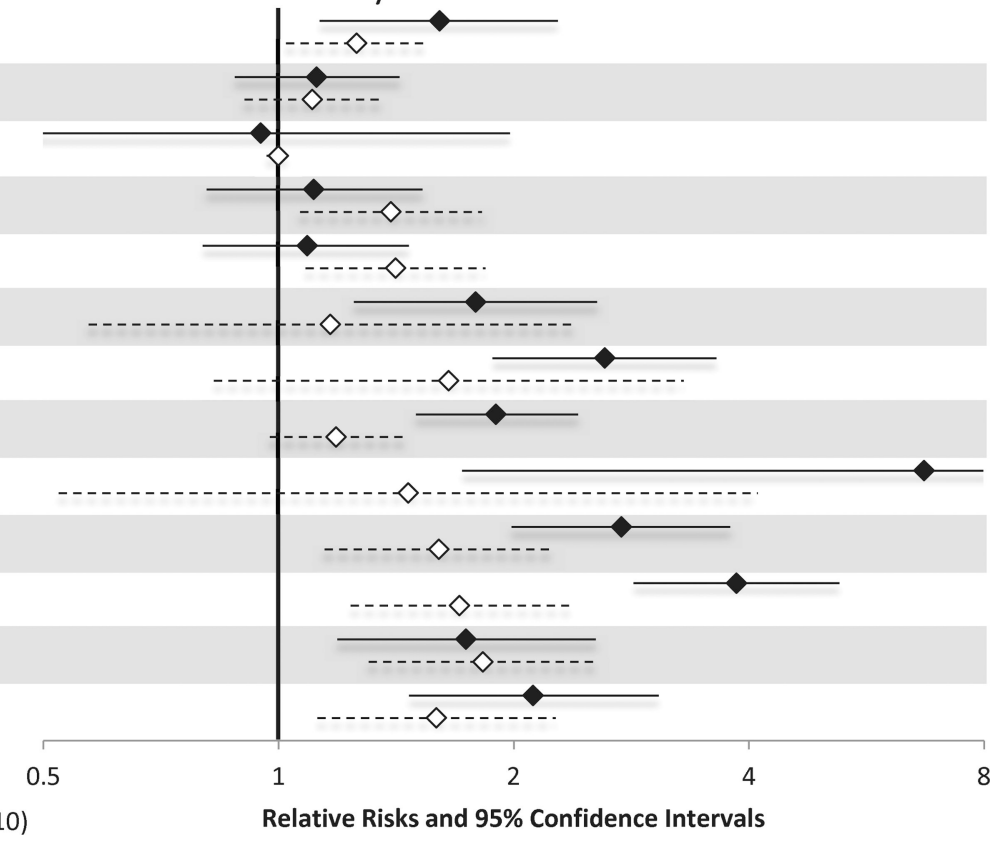


C Psychological and Cognitive Characteristics

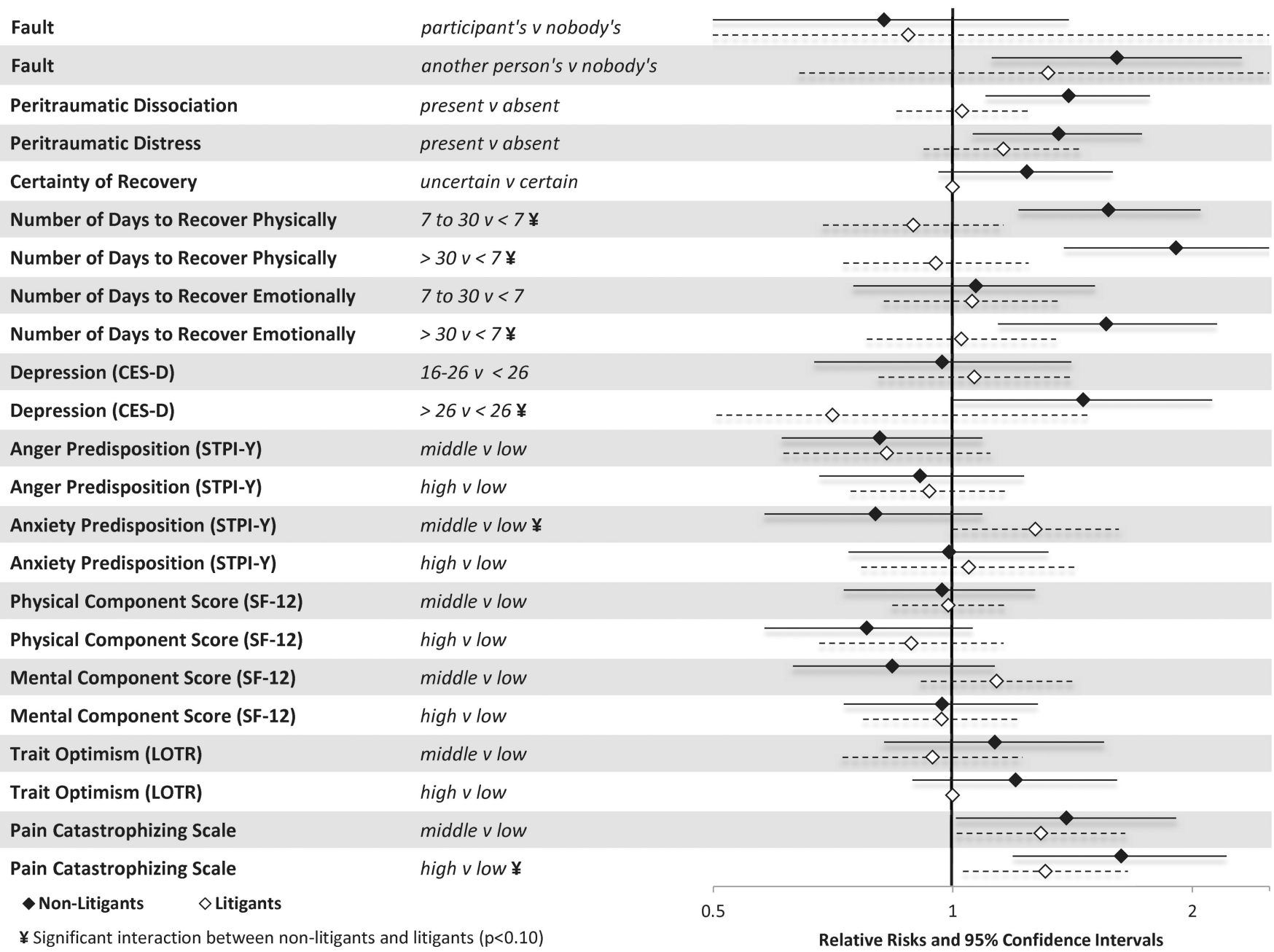

Figure 3.

Associations between baseline characteristics (evaluated in the emergency department in the hours after motor vehicle collision) and moderate or severe neck pain at six weeks among individuals not seeking compensation ("non-litigants", $\mathrm{n}=859$ ) and individuals seeking compensation ("litigants", $n=148$ ) after motor vehicle collision. Characteristics investigated include (A) sociodemographic and crash characteristics (B) pain and somatic symptoms reported prior to and in the immediate aftermath of MVC and (C) psychological and cognitive characteristics. *Category listed second is reference group 
A sociodemographic and CRASH characteristics

\begin{tabular}{|c|c|c|c|}
\hline Age & 28 to $41 \mathrm{v} 18$ to 27 & $\cdots-\cdots-$ & $----\cdots$ \\
\hline Age & 42 to $65 v 18$ to 27 & --- & $\diamond \cdots \cdots$ \\
\hline Sex & female $\vee$ male $¥$ & --- & $\diamond-\cdots$ \\
\hline Health Insurance & yes $v$ no & $---\diamond-\cdots--$ & \\
\hline Education & some college $v$ high school/less & $-\cdots$ & $---\diamond-----------$ \\
\hline Education & college/post-grad v high school/less & $-\cdots$ & 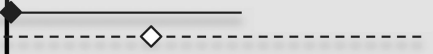 \\
\hline Income & $\$ 20 k$ to $\$ 40 k v<\$ 20 k$ & -- & 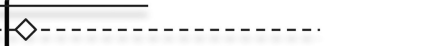 \\
\hline Income & $\$ 40 k$ to $\$ 80 k v<\$ 20 k$ & --- & $-\diamond \cdots \cdots$ \\
\hline Income & $>\$ 80 k v<\$ 20 k$ & & $-\cdots \diamond-\cdots$ \\
\hline Work Full Time & yes $v$ no & ------ & \\
\hline Ever Smoked & yes v no & & $-1-1$ \\
\hline Collision Type & rear-ended $v$ other & & $-\cdots--\diamond \cdots$ \\
\hline Vehicle Damage & moderate $v$ none/minor & $\cdots-\cdots-\triangleleft$ & $-\ldots-\ldots$ \\
\hline Vehicle Damage & severe $v$ none/minor & $------\diamond_{-\cdots}$ & - \\
\hline Vehicle Speed & 1 to $40 \mathrm{mph} v$ stopped & $-\cdots----\diamond_{-1}$ & -- \\
\hline Vehicle Speed & 41 to $80 \mathrm{mph} v$ stopped & & $p--$ \\
\hline Vehicle Seat & driver $v$ passenger & & $p-\cdots \cdots \cdots-\cdots$ \\
\hline$\diamond$ Non-Litigants & $\diamond$ Litigants & 0.5 & 2 \\
\hline
\end{tabular}

B Pain and Somatic Symptoms Reported Prior to MVC and immediately after MVC

Prior Neck Pain

Any Prior Regional Pain

Prior Widespread Pain

Prior Somatic Symptoms

Prior Somatic Symptoms

Overall Pain in the ED

Overall Pain in the ED

Widespread Pain in the ED

Any Regional Pain in the ED

Neck Pain in the ED

Neck Pain in the ED

Somatic Symptoms in the ED

Somatic Symptoms in the ED

Non-Litigants

$\diamond$ Litigants

present $v$ absent

present $v$ absent

present $v$ absent

middle $v$ low

high v low

moderate $v$ none/mild $¥$

severe $v$ none/mild

present $v$ absent $¥$

present $v$ absent

moderate $v$ none/mild

severe $v$ none/mild

middle $v$ low

high $v$ low

$¥$ Significant interaction between non-litigants and litigants $(p<0.10)$

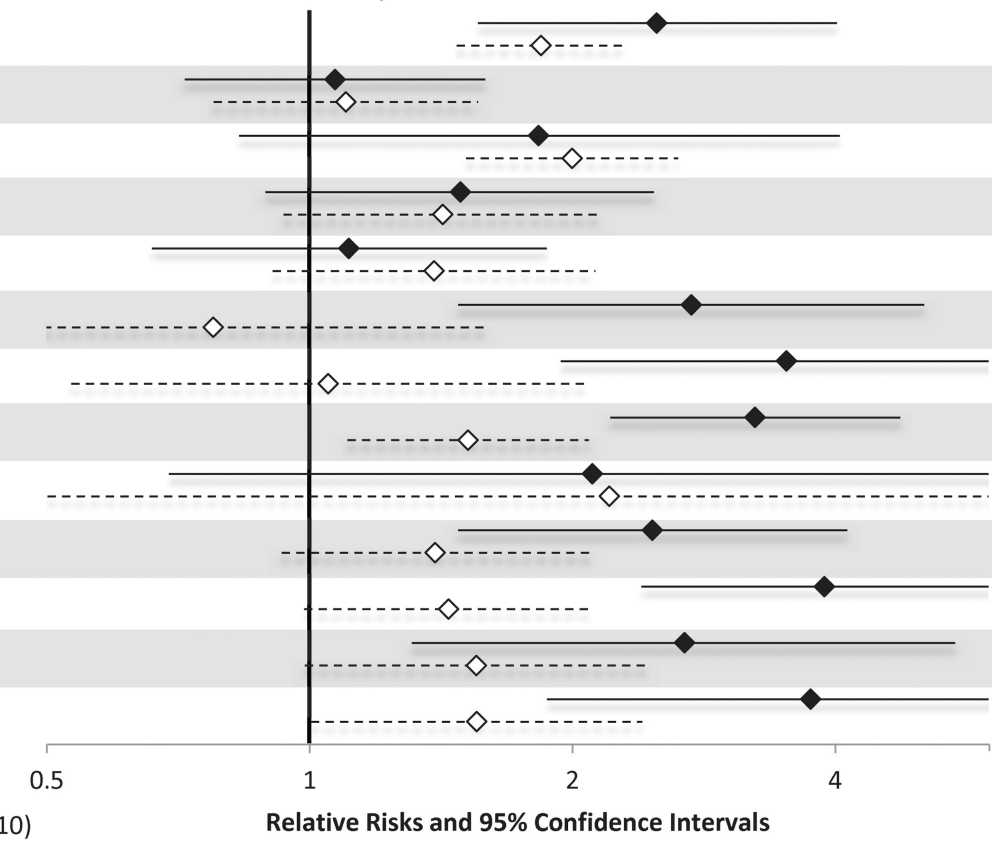


$C_{\text {Psychological and Cognitive Characteristics }}$

\begin{tabular}{|c|c|c|c|}
\hline Fault & participant's v nobody's & 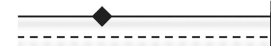 & $-\ldots$ \\
\hline Fault & another person's v nobody's & & 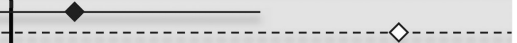 \\
\hline Peritraumatic Dissociation & present $v$ absent & -- & 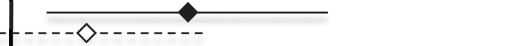 \\
\hline Peritraumatic Distress & present $v$ absent & $-\cdots--\diamond$ & $-\cdots$ \\
\hline Certainty of Recovery & uncertain $v$ certain $¥$ & $-\cdots---\diamond-\overline{-}$ & -- \\
\hline Number of Days to Recover Physically & 7 to $30 v<7 ¥$ & & $-\diamond-\cdots-$ \\
\hline Number of Days to Recover Physically & $>30 v<7 ¥$ & $-\cdots---\Delta\rangle$ & 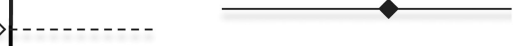 \\
\hline Number of Days to Recover Emotionally & 7 to $30 v<7$ & & $-\diamond-\cdots$ \\
\hline Number of Days to Recover Emotionally & $>30 v<7 ¥$ & $-------\diamond---$ & $-\cdots$ \\
\hline Depression (CES-D) & $16-26 v<26$ & $---\cdots--\diamond-$ & -1 \\
\hline Depression (CES-D) & $>26 v<26$ & & $\cdots--\diamond \cdots$ \\
\hline Anger Predisposition (STPI-Y) & middle $v$ low $¥$ & $\cdots-\cdots$ & $\rightarrow$ \\
\hline Anger Predisposition (STPI-Y) & high v low $¥$ & --1 & --- \\
\hline Anxiety Predisposition (STPI-Y) & middle $v$ low $¥$ & & $---\diamond-\cdots \cdots$ \\
\hline Anxiety Predisposition (STPI-Y) & high v low & $-\cdots-\cdots---$ & $-\cdots$ \\
\hline Physical Component Score (SF-12) & middle $v$ low & $\cdots-\cdots$ & $-\ldots$ \\
\hline Physical Component Score (SF-12) & high v low $¥$ & $-\cdots$ & $+--\diamond-\cdots-\cdots$ \\
\hline Mental Component Score (SF-12) & middle $v$ low $¥$ & $-\cdots$ & $f--\diamond \cdots$ \\
\hline Mental Component Score (SF-12) & high v low & $-\cdots$ & 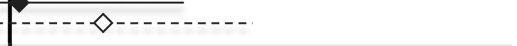 \\
\hline Trait Optimism (LOTR) & middle $v$ low & & 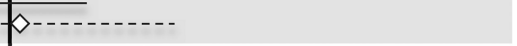 \\
\hline Trait Optimism (LOTR) & high v low & --- & $-\cdots \diamond \cdots$ \\
\hline Pain Catastrophizing Scale & middle $v$ low & ----- & $--\diamond \cdots \cdots$ \\
\hline Pain Catastrophizing Scale & high v low $¥$ & 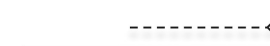 & $\gamma-\cdots \cdots$ \\
\hline$\diamond$ Non-Litigants $\quad \diamond$ Litigants & & 0.5 & 1 \\
\hline
\end{tabular}

Figure 4.

Associations between baseline characteristics (evaluated in the emergency department in the hours after motor vehicle collision) and widespread pain at six weeks among individuals not seeking compensation ("non-litigants", $\mathrm{n}=859$ ) and individuals seeking compensation ("litigants", $\mathrm{n}=148$ ) after motor vehicle collision. Characteristics investigated include (A) sociodemographic and crash characteristics (B) pain and somatic symptoms reported prior to and in the immediate aftermath of MVC and (C) psychological and cognitive characteristics. *Category listed second is reference group 
A Multivariate Predictive Model of MSNP in Non-Litigants

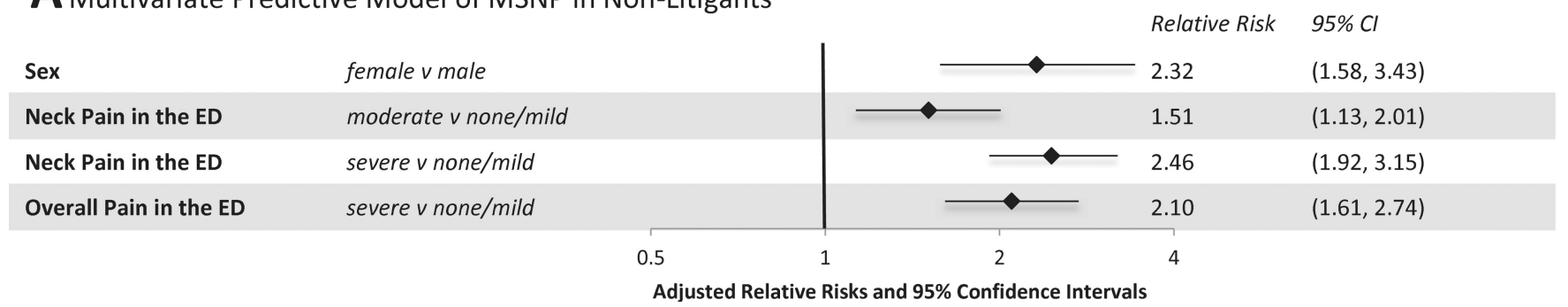

\section{B Multivariate Predictive Model of MSNP in Litigants}

\begin{tabular}{|c|c|c|c|c|c|}
\hline Sex* & female $v$ male & & $\mid-\cdots-\infty-\cdots$ & 1.29 & $(1.00,1.67)$ \\
\hline Age* & 42 to $65 \vee 18$ to 27 & -- & $--\diamond-\cdots$ & 1.15 & $(0.90,1.46)$ \\
\hline Neck Pain in the ED* & moderate $v$ none/mild & -- & $---\diamond-\cdots$ & 1.15 & $(0.93,1.43)$ \\
\hline Neck Pain in the ED & severe $v$ none/mild & & $\cdots-\cdots-\cdots-\cdots$ & 1.34 & $(1.08,1.67)$ \\
\hline Overall Pain in the ED & severe $v$ none/mild & & $\cdots-\cdots \diamond-\cdots-1$ & 1.44 & $(1.12,1.86)$ \\
\hline Peritraumatic Distress* & present $v$ absent & --- & $--\diamond-\cdots-\cdots$ & 1.13 & $(0.87,1.47)$ \\
\hline Anger Predisposition (STPI-Y)* & middle v low & $\cdots-\cdots---$ & --- & 0.83 & $(0.61,1.13)$ \\
\hline Anger Predisposition (STPI-Y)* & high v low & $\cdots--\diamond-$ & --- & 0.90 & $(0.70,1.15)$ \\
\hline Work Full Time & yes $v$ no & $-\cdots \diamond-\cdots$ & & 0.79 & $(0.67,0.93)$ \\
\hline Collision Type & rear-ended $v$ other & & $\cdots----\cdots$ & 1.31 & $(1.06,1.61)$ \\
\hline Health Insurance & yes $v$ no & $\cdots-\cdots-\cdots$ & & 0.66 & $(0.53,0.83)$ \\
\hline Vehicle Seat & driver $v$ passenger & $\cdots-\cdots-\cdots$ & & 0.74 & $(0.59,0.93)$ \\
\hline & & & 1 & 2 & \\
\hline
\end{tabular}

*putative risk factors were retained by LASSO, but they are not significant in this model

\section{Multivariate Predictive Model of WP in Non-Litigants}

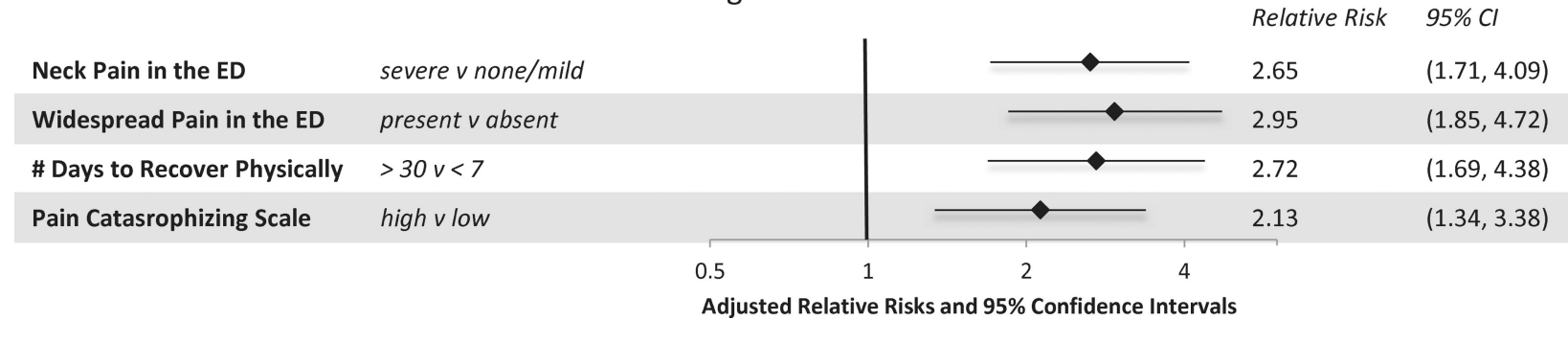

D Multivariate Predictive Model of WP in Litigants

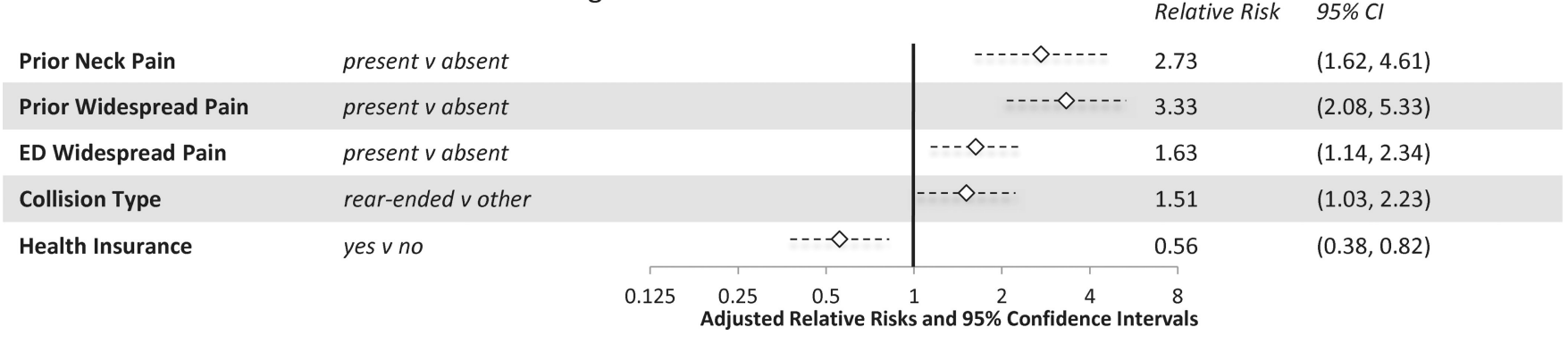

Figure 5.

Pain. Author manuscript; available in PMC 2015 February 01. 
Multivariate Predictive Models of MSNP and WP six weeks after MVC 
A

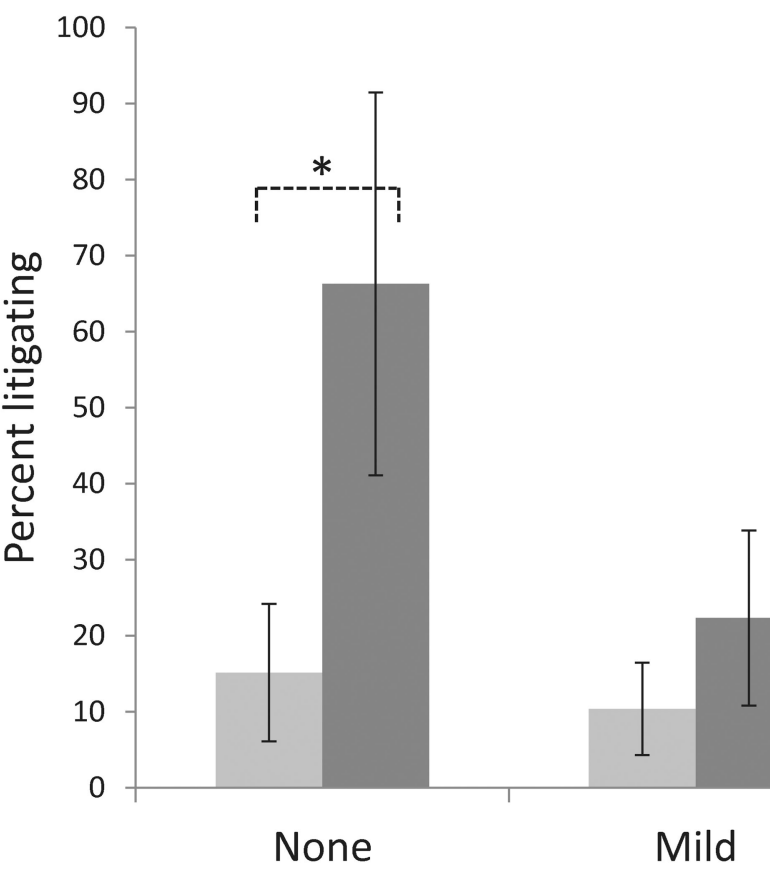

B

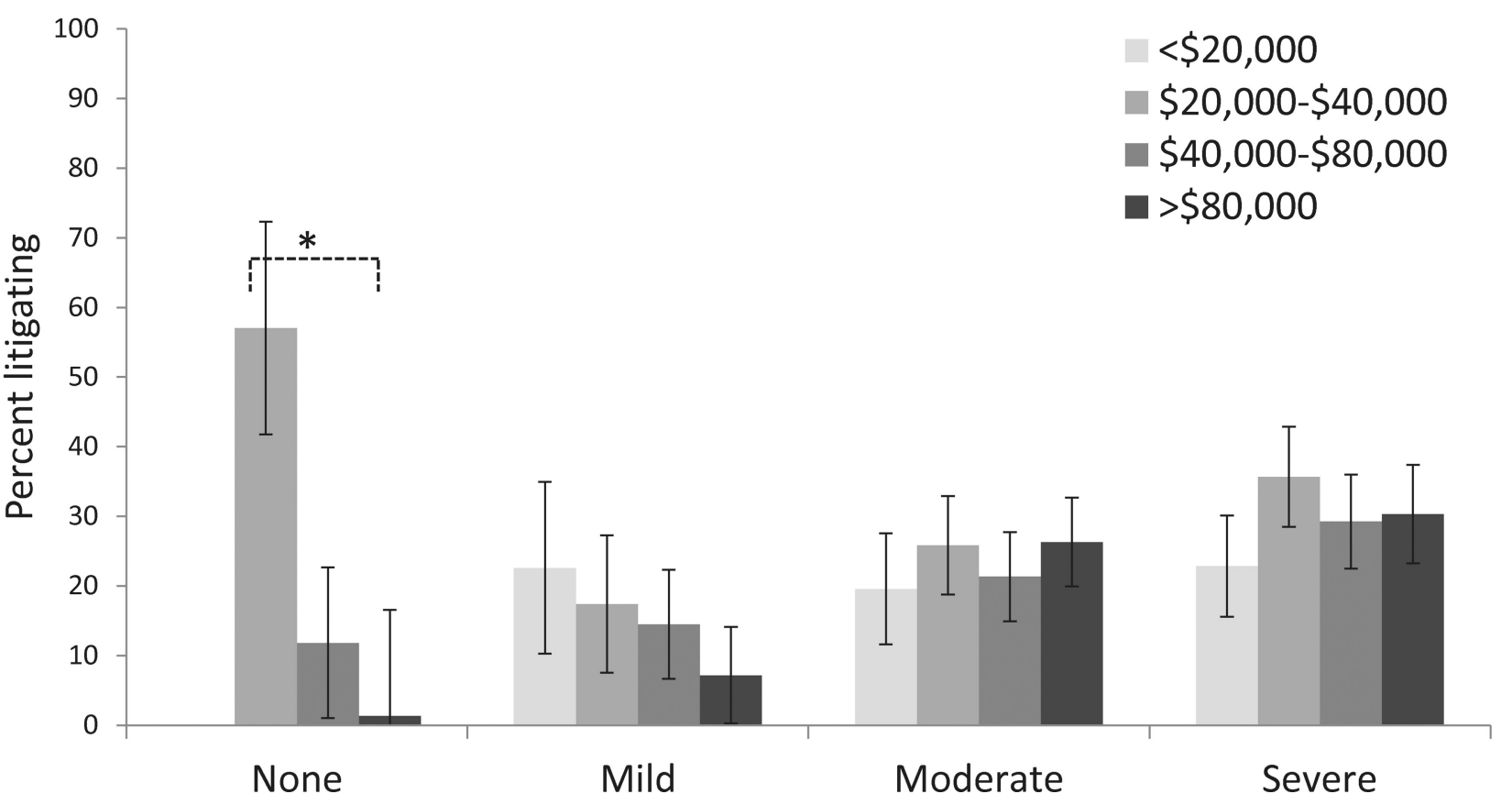

Figure 6.

Percent of individuals reporting engagement in litigation six weeks after motor vehicle collision according to overall pain severity in the ED (no pain ( 0 on NRS), mild pain (1-3.5 on NRS), moderate pain (4-6.5 on NRS), or severe pain (7-10 on NRS)) and health insurance status (Panel A) and income (Panel B). Results adjusted for age, sex, and state where participant recruited. *Comparisons designed with an asterix are significant at $\mathrm{p}<$ 0.05 . 


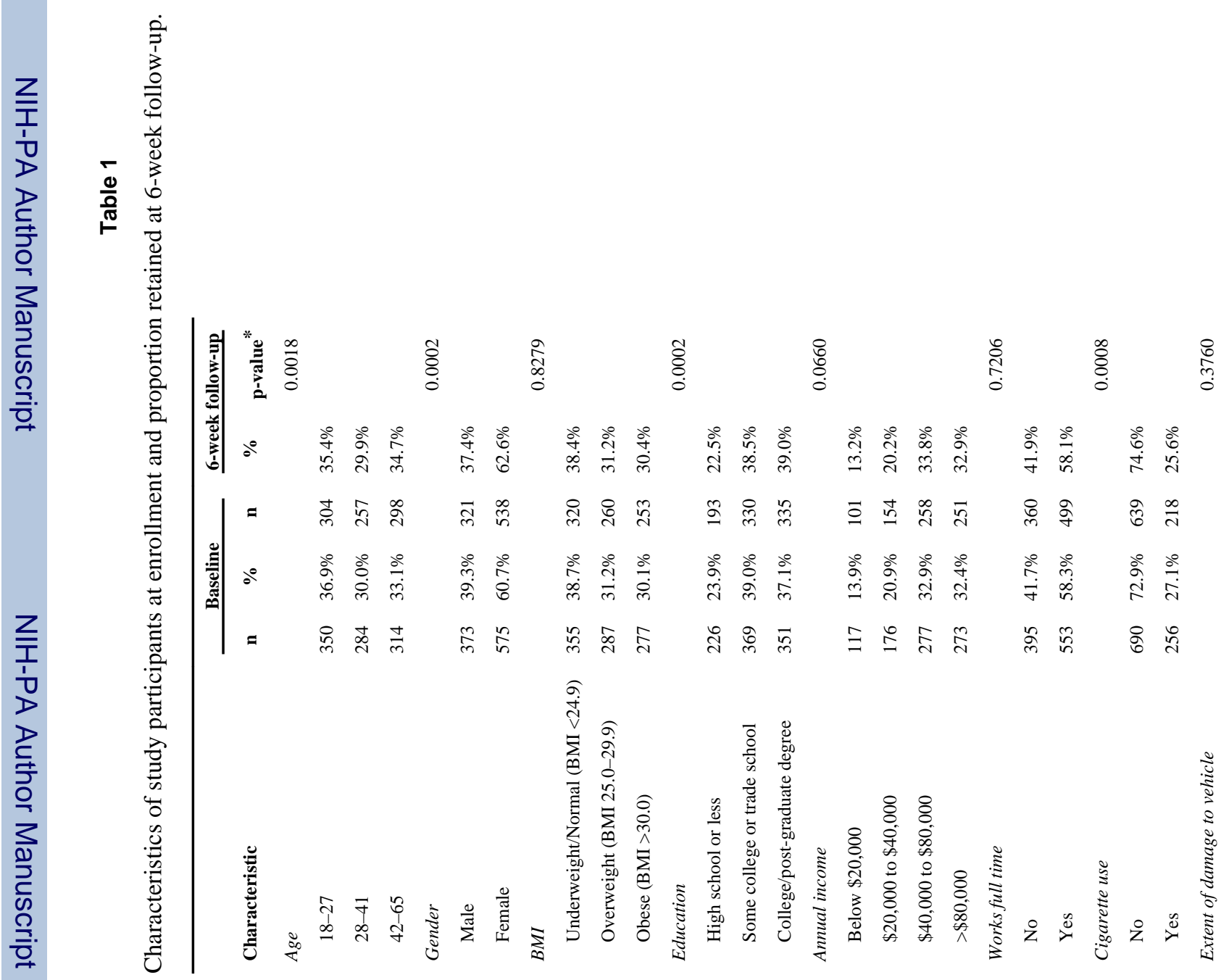
Pain. Author manuscript; available in PMC 2015 February 01. 


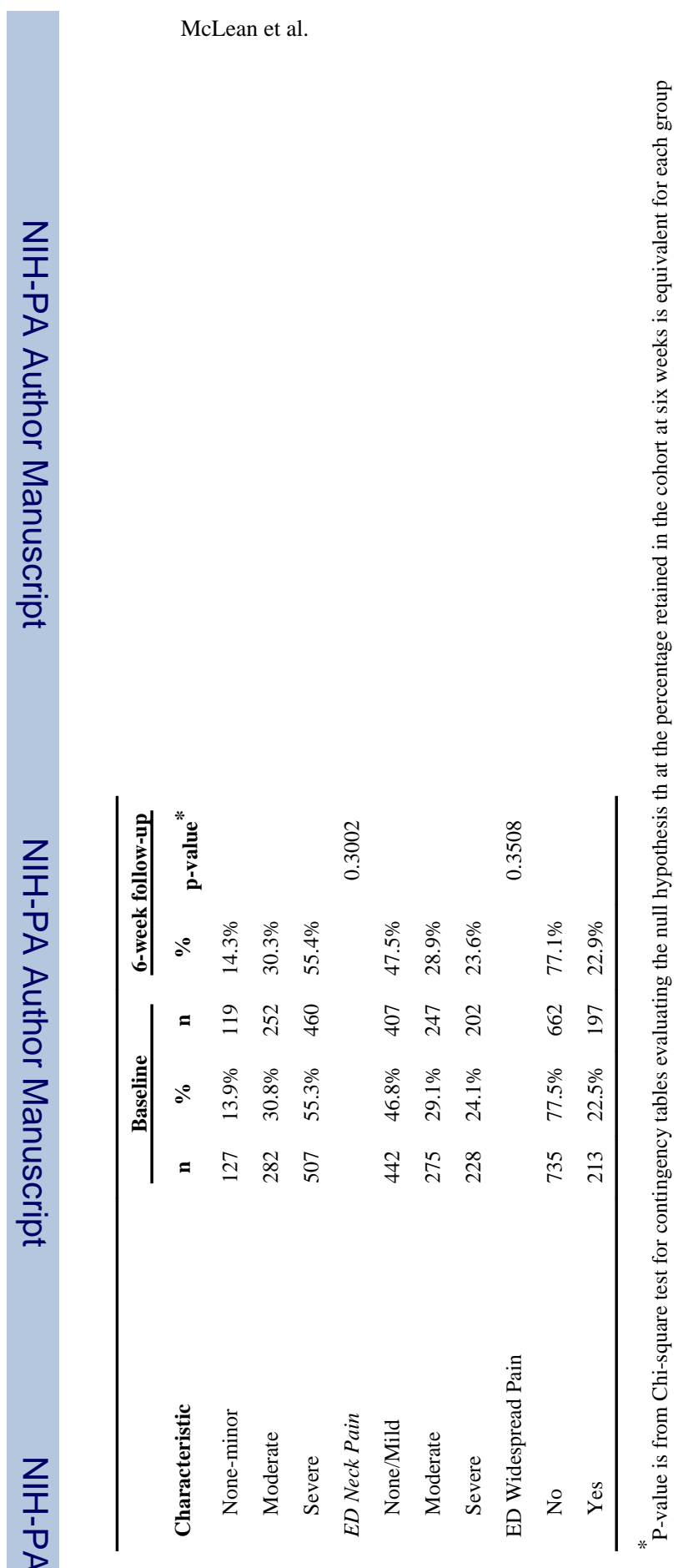

Pain. Author manuscript; available in PMC 2015 February 01. 